\title{
Management of complex proximal humerus fractures in the elderly: what is the role of open reduction and internal fixation?
}

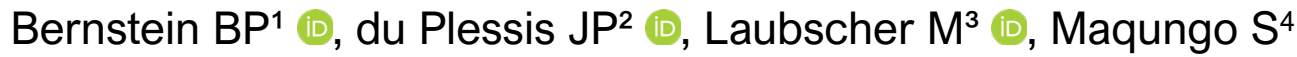

1 MBBCh(Wits)FCS(SA)Orth; 1: Cape Orthopaedic Trauma Group. Life Orthopaedic Hospital, Alexandra road, Pinelands, 7405, Cape Town, South Africa; 2: Orthopaedic Research Unit, Department of Orthopaedic Surgery, Groote Schuur Hospital, University of Cape Town, Cape Town, South Africa

2 MBChB(UCT), Dip PEC, FC Orth (SA), MMed Ortho (UCT); 1: Orthopaedic Research Unit, Department of Orthopaedic Surgery, Groote Schuur Hospital, University of Cape Town, Cape Town, South Africa; 2: Orthopaedic Department, New Somerset Hospital, Cape Town; 3: Life Orthopaedic Hospital, Cape Town

3 MBChB(UFS), Dip PEC, FC Orth (SA), MMed Ortho (UCT); Orthopaedic Research Unit, Department of Orthopaedic Surgery, Groote Schuur Hospital, University of Cape Town, Cape Town, South Africa

$4 \mathrm{MBChB}$ (Natal), FC Orth (SA), MMed Ortho (UCT); Orthopaedic Research Unit, Department of Orthopaedic Surgery, Groote Schuur Hospital, University of Cape Town, Cape Town, South Africa

Corresponding author: Dr BP Bernstein, Life Orthopaedic Hospital, Park Road, Pinelands, 7405, Cape Town, South Africa; PO Box 599, Constantia, 7848, South Africa; email: bb@otg.org.za

\begin{abstract}
The ultimate goal of management of proximal humeral fractures in the elderly patient is to get the patient independently mobile. This article will review the current literature regarding this cohort of patient. Recent Cochrane reviews and a large multicentre randomised study question the role of surgical intervention. Implant design is evolving rapidly, and many elderly patients now behave more like the younger patient. There remains little compelling evidence to guide decision-making for the complex proximal humeral fracture in the elderly, and the decision needs to be made on a case-by-case basis taking into account the patient's comorbidities, the fracture pattern and characteristics, the attending surgeon's skill sets, and the availability of equipment.
\end{abstract}

Level of evidence: Level 5

Key words: proximal humerus fracture, fragility fracture, osteoporosis, implant evolution, internal fixation

Citation: Bernstein BP, du Plessis JP, Laubscher M, Maqungo S. Management of complex proximal humerus fractures in the elderly: what is the role of open reduction and internal fixation? SA Orthop J 2019;18(2):37-43. http://dx.doi.org/10.17159/2309-8309/2019/v18n2a4

Editor: Prof LC Marais, University of KwaZulu-Natal, Durban, South Africa

Received: February 2019

Accepted: April 2019

Published: May 2019

Copyright: ( 2019 Bernstein BP, et al. This is an open-access article distributed under the terms of the Creative Commons Attribution Licence, which permits unrestricted use, distribution and reproduction in any medium, provided the original author and source are credited.

Funding: None.

Conflict of interest: There were no conflicts of interest for any author with respect to this review. 


\section{Introduction}

The ultimate goal of management of proximal humeral fractures in the elderly patient is to get the patient independently mobile. This relies on a multidisciplinary team approach in which operative intervention may or may not be indicated.

Elderly patients may not tolerate prolonged immobilisation, and in addition, sling immobilisation affects balance and may increase the risk of falling.

Fixation of osteoporotic bone is different to that of physiologically normal bone. Fracture healing takes a longer time, the implant fixation in the bone is compromised, and fracture patterns may be more complex, with surgery becoming more technically demanding. This combination of factors may lead to progressive failure at the bone implant interface, implant migration and fracture displacement. ${ }^{1-4}$

Indications for surgery vary a great deal from study to study, and are often ill defined. Identification of risk factors for poor outcomes is important, including the identification of poor bone mineral density and the possibility of developing avascular necrosis.

\section{Incidence}

There is an increasing incidence of proximal humerus fracture rates and a decline in hip fractures in patients over 50 years of age. ${ }^{5}$

Proximal humerus fractures are reported to be the third most common osteoporotic fracture excluding spine and the second most common upper extremity fragility fracture. It is reported that $73 \%$ occur in females. ${ }^{6,7}$

In a recent prospective study of 5147 women with osteoporotic fractures, undisplaced proximal humerus fractures comprised $17.5 \%$ and were the third most frequent fracture after distal radius and vertebral fractures. Patients over the age of 70 years showed a decrease in the incidence of distal radius and vertebral fractures, but not proximal humerus fractures. ${ }^{8}$

\section{Osteoporosis}

Osteoporosis results in altered microarchitecture and a decreased bone mass which is caused by an imbalance in the bone resorption and formation. In addition, there are intrinsic changes such as altered collagen cross linkage and distribution of mineralisation which contributes to the decreased bone strength and modulus of elasticity. The resultant increased bone fragility increases fracture risk. Stiffness of bone alters by $1-2 \%$ per decade, and the strength of bone decreases by $2-5 \%$ per decade. The energy required to cause a fracture decreases by up to $10 \%$ per decade over the age of 35 years. ${ }^{9}$

Osteoporosis is the most common bone disease in the US. ${ }^{10}$ The costs relating to management of osteoporotic fractures is significant, and these fractures are an important cause of morbidity and mortality.

The diagnosis of osteoporosis is largely based around hip and spine bone mineral density, and the diagnostic criteria in relation to proximal humerus fractures is less clear. ${ }^{11}$

A proximal humerus fracture may be the presenting complaint in a patient with osteoporosis, and allow its diagnosis. This opportunity should not be missed.

There is a six-fold increased risk of developing a hip fracture in the first year after a proximal humerus fracture. ${ }^{7}$

Bisphosphonate treatment has been shown to reduce the risk of a fragility fracture by up to $70 \%$ in patients with osteoporosis. ${ }^{12,13}$ Despite this, the initiation of anti-osteoporosis treatment following upper limb fragility fractures is low. ${ }^{8,14}$
This is in contrast to the reported increased initiation of treatment in patients who suffer vertebral or hip fracture..$^{15}$

This implies that patients with osteoporotic proximal humerus fractures are an important group to identify and manage.

The disease burden of osteoporosis is large both in terms of the impact on the individual, and the cost to society. Managing these patients appropriately may enable a reduction in the risk of subsequent fragility fractures, and improve the individual patients' quality of life.

As indications for management, including surgery, vary a great deal, a comprehensive classification system is required.

Many clinical studies base their indications on the amount of displacement as defined by Neer in $1970 . .^{16,17}$

Other studies have a lower threshold for surgical fixation with indications including $0.5 \mathrm{~cm}$ of tuberosity displacement, medial metaphyseal comminution ${ }^{18}$ or humeral head angulation of $>30^{\circ},{ }^{19}$ and although it has been suggested in some studies that operative management is the preferred method of treatment in displaced fractures, with conservative treatment resulting in 'consistently inferior results', ${ }^{1}$ there is much evidence against this.

Studies have shown that the surgeon's interpretation of displacement was variable and arbitrary ${ }^{20}$ and the benefit of surgery over conservative treatment has been questioned. ${ }^{20,21}$

\section{Classification}

Neer's modification of Codman's classification relies on identification of four potential parts and their displacement (shaft/ articular surface/greater tuberosity/lesser tuberosity).

Despite poor intra- and inter-observer reliability, it remains the most commonly utilised classification system.

More comprehensive classification systems have been developed, including the morphological system by Hertel, ${ }^{22}$ but their usage in clinical practice remains limited.

\section{Management options}

As mentioned, the management options include non-surgical and surgical modalities, and we ideally need to know if the bone quality is sufficient for internal fixation to support and maintain fracture reduction. Indices utilising the cortical thickness of the proximal humerus on plain radiograph have been validated to predict both local and general decreased bone mineral density. ${ }^{23,24}$

The cortical index ${ }^{24}$ is a ratio of medial and lateral cortical thickness to total humeral width measured at $10 \mathrm{~cm}$ distal to the tip of the greater tuberosity. The cortical bone thickness average (CBT avg ${ }^{23}$ takes measurements of the combined cortical thickness (medial and lateral cortical thickness) at two levels and averages them. The initial level of measurement is the most proximal point on the humeral shaft where the medial and lateral cortices are parallel and the second level is $20 \mathrm{~mm}$ below that. These measurements have been shown to be easily reproducible on simple anteroposterior radiographs of the proximal humeral shaft.

A recent advance is the ability to quantify the bone mineral density using CT scan evaluation of the proximal humerus. ${ }^{25}$ It was found that a bone mineral density value of $95 \mathrm{mg} / \mathrm{cm}^{3}$ was the cut-off, below which implant failure was likely to occur. As many centres use CT scan as part of the pre-operative workup, these recommendations could have useful practical implications. ${ }^{26}$ The mode of failure in osteoporotic bone is more likely to be failure of the bone than of the implant itself.

Factors which predispose to internal fixation failure in the proximal humerus include low bone mineral density, varus malreduction, avascular necrosis, poor medial column restoration and nonanatomic reduction. ${ }^{27}$ 
The options available for the surgical management of the proximal humerus are many and varied, which in itself is an indication of the technical difficulty and variable outcomes of each modality.

Anatomical fixed angle plates, intramedullary nails, minimally invasive screw or wiring constructs and arthroplasty (both hemi and reverse) have all been described. In addition, fixation may be augmented with bone cement, intramedullary fibula strut grafts or cortico-cancellous iliac crest grafts.

\section{K-wires}

The benefit of K-wire fixation after closed reduction is that there is relatively little surgical insult and exposure, and minimal soft tissue damage. This may reduce the risk of avascular necrosis..$^{19,28}$ However, the thin cortices may not provide enough purchase for fixation, and loss of reduction may ensue. ${ }^{28}$ Resch et al. describe a technique utilising the humerus block to provide lateral fixation and angular stability to the K-wires ${ }^{29}$ and it is felt the relative stability achieved may in fact be an advantage in osteoporotic bone where rigid implants can cut out, or promote non-union. This technique relies on soft tissue bridging between the fragments, and appears to be more suitable for valgus impaction fractures.

Resch himself reports good results in three-part fractures, but in four-part fractures this is a technically demanding technique and is not widely employed. ${ }^{19}$

\section{Plates}

Since the introduction of locked plate technology (angular stable constructs) the rate of fixation of proximal humeral fractures has increased.

Although the majority (84\%) of fractures are managed conservatively there has been a relative increase of $28.5 \%$ of fractures that underwent open reduction and internal fixation (ORIF) between 2004 and 2005 when compared to 1999-2000.30

It is worth noting that the rate of revision surgery has increased as well.

This increase may not be related only to advances in technology, as other factors such as patient and surgeon expectations and the fracture patterns related to active lifestyles may also have contributed to this increasing surgical trend..$^{28}$

Fixed angle anatomic locking plates have become the most commonly utilised implants for fixation of proximal humerus fractures. ${ }^{20,31}$

The mode of failure of locked plates differs from conventional plates which will fail by the loosening of individual screws sequentially whereas locked plates will fail by simultaneous cut-out of multiple screws or by fracture of the bone at the stress riser at the end of the plate. ${ }^{32}$

It has been shown that good restoration of support to the inferomedial calcar is important in maintaining fracture reduction. ${ }^{33-35}$

Early loss of reduction remains a problem and was noted in $22.5 \%$ of cases, with a strong correlation to the amount of impaction, female sex, and metaphyseal comminution.

This highlights that surgical technique and implant placement are important. The screws should be placed in such a way so that they gain as much purchase as possible in subchondral bone.

After reduction of the osteoporotic fracture, a residual cavity is often created. Some authors advocate the use of adjuncts to fill this defect. Calcium phosphate and bone graft (cancellous or fibula strut) have been used. Attention to reduction technique may limit the size of the resultant bone defect. ${ }^{2}$
Early good results with locked plates ${ }^{17}$ were tempered by studies reporting complication rates as high as $21 \%,{ }^{18}$ and even as high as $37 \%,{ }^{36}$ with a $20 \%$ re-operation rate.

All the studies seem to report worse outcomes with four-part fractures, and it appears that two-part fractures tend to do well.

The variation in indications for surgery and the type of fractures managed in most of these studies makes comparative interpretation of the reported results challenging.

The proximal humerus plate has gone through a number of evolutionary changes in an attempt to improve the outcomes. The initial clover leaf plates did not have angular stability and have been replaced by fixed angle locking plates with divergent screws, low anatomic profiles, suture holes for the attachment of tension band sutures and rotator cuff sutures, and now variable angle locking screw options, medial calcar support screws and cannulated screws to allow delivery of cement into the fracture site.

New technology continues to be introduced with the latest being investigation into the use of different materials such as PEEK (polyetheretherketone) plates. PEEK has a modulus of elasticity much closer to bone than titanium or stainless steel, and it is postulated that this material will allow the development of a plate with the benefits of angular stability for the screws, but reduced implant stiffness to reduce the stress riser affect and allow biological healing of the fracture. ${ }^{37}$

As an adjunct to fixation with plate or nails, tension band suture fixation of the rotator cuff and tuberosities has been shown to improve outcomes. ${ }^{38-40}$

\section{Nails}

In general, the surgical management of insufficiency fractures is best achieved by an implant that is load sharing. The intramedullary nail is such a load-sharing device. In addition, the more medial position of the implant, shorter lever arm in the humeral head, and better preservation of blood supply, soft tissue and periosteum would infer that this is the better implant to utilise. However, there are problems associated with its use in osteoporotic bone and insufficiency fractures because the fracture configuration is often complex and unstable with comminution of the lateral cortex, which may lead to secondary displacement and failure. Post-fixation shoulder pain related to damage to the rotator cuff insertion and impingement remains an unsolved issue. .,41-43 $^{-4}$

A recent meta-analysis concluded that although satisfactory clinical results can be achieved utilising nails in two- and threepart fractures of the proximal humerus, re-operation rates were $15.8 \%$ and complication rates were as high as $42.5 \%, 28 \%$ of which were related to loss of reduction, screw perforation or malunion. In four-part fractures the re-operation rates were as high as $63.2 \%$, and there were 29 complications in 33 patients They concluded that the use of intramedullary nails 'for four-part fractures cannot be recommended'. In this meta-analysis, there was no study that included a non-operative control group and only 33 of a total of 448 patients had four-part fractures which were managed with intramedullary nails. This probably is a reflection that the general orthopaedic community is in agreement with their conclusions. ${ }^{44}$

Good outcomes have been reported for fracture fixation with intramedullary nails but elderly patients tend to have poorer functional results and increased complications. ${ }^{45}$

Nail design may impact on outcomes as straight nails have been shown to have better outcomes in terms of range of motion than curved nails, and the more medial insertion addresses the lateral cortex comminution better. ${ }^{46}$ There is, however, no statistical difference in the outcomes in a recent randomised controlled clinical trial comparing curved to straight nails. ${ }^{47}$ 
The use of threaded bushings to minimise screw back-out and provide more angular stability in osteoporotic bone has been proposed. 43

One of the most important goals of proximal humerus fracture fixation is to restore the medial calcar to prevent varus collapse. New generation nails are starting to incorporate more distal locking screws or a blade to support the medial calcar to prevent this mode of failure. ${ }^{1}$ The distal screw constructs may, however, put the axillary nerve at risk. ${ }^{48}$

The design of intramedullary proximal humeral nails has advanced a great deal recently in recent years. Modifications have included:

- straighter nails

- nylon bushings and end caps to confer angular stability

- more distal screws and blades angled superiorly

- suture anchor points on the screw or blade heads

- varied and divergent proximal screw placement. ${ }^{41}$

Comparative studies of plate versus nail fixation have been performed. A recent study testing the biomechanics in sawbones shows higher stiffness and load to failure in nails over plates, ${ }^{43}$ but this does not take the soft tissue repair into account. Clinical studies including large meta-analysis and Cochrane reviews have found little to support one over the other, and both appear to be viable options in the two- and three-part fractures, although fourpart fractures may require a different approach. ${ }^{49}$

\section{Augmentation}

Many different augments have been used in an effort to optimise the fracture stability, fill defects and promote anatomic healing. This is largely driven by the complications of implant failure and loss of reduction seen in all the surgical options. The most common augments utilised currently are fibula strut grafts, calcium phosphate and PMMA (polymethyl methacrylate) cement.

Implants have been adapted and designed to accommodate these augments, such as the perforated cannulated screws and blades to allow for the delivery of cement to the screw tips and humeral head defects.

Anteromedial and anteroinferior screws have been shown to have the lowest breakaway torque and provide the greatest resistance to displacement when two of these screws are used for augmentation. 50,51

Biomechanical studies have shown that a corticocancellous bone block contributes to the stability of two-part fractures with a medial fracture gap by increasing the stiffness and load to failure. ${ }^{52}$

In-vitro studies have shown that filling the fracture void with calcium triphosphate cement using PMMA augmentation with plates and nails decreases the risk of screw pull-out and loss of reduction. . $3-55^{-5}$

Fibula struts show promise, although clinical studies in the current literature are of a small sample size. ${ }^{56,57}$

Femoral head allograft augmentation has shown similar results in a group of ten patients, with an average post-op constant score of 72 at 28 months, and one non-union (10\%). ${ }^{58}$

Although clinical results are promising, these techniques are not without complications, ${ }^{59}$ and there are no studies with a control group to allow for comparison. This makes the interpretation of results difficult.

Concerns regarding late removal of implants following the use of augments such as bone cement appear unfounded. ${ }^{60}$

Bone morphogenic proteins and biomaterials may become useful adjuncts as BMPs are thought to be involved in the development of osteoporosis, but at this stage the literature is limited to preclinical trials. ${ }^{61}$
It seems that current opinion will concur that it does not matter what technique of fixation is employed, or which augmentation method utilised. Good outcomes will still rely on anatomic reduction of the tuberosities and the humeral head.

No amount of augmentation or implant evolution will compensate for poor surgical technique.

The recommendation of the recent reviews is that medial support screws should be used in all cases as they seem to confer improved biomechanical stability by supporting the medial calcar and do not add to the surgical insult.

With regard to augmentation, there is insufficient evidence to support their use, although they do appear to have a stabilising effect. ${ }^{62}$

\section{Soft tissue}

Attention to the status of the soft tissue, and meticulous closure and dressing care in the elderly patient with thin skin is important, and the decision and timing of surgery must take this into account.

\section{Arthroplasty}

A full discussion on the use of arthroplasty in the treatment of proximal humerus fractures is beyond the scope of the title of this article, but as this is a developing option a few points must be mentioned.

There is a documented increase in the use of primary arthroplasty to manage the complex proximal humerus fracture and as with plate and nail fixation, good results have been shown to rely on healing of the tuberosities in an anatomical position. This is particularly relevant when it comes to the use of hemiarthroplasty.

There has been a steadily increasing use of the reverse shoulder replacement in an attempt to bypass the requirements of tuberosity healing in fractures treated with hemiarthroplasty. ${ }^{30,63}$

As with the other treatment modalities the latest Cochrane review does not find enough evidence to recommend the use of one modality over the other, nor is there enough evidence to advise arthroplasty over conservative treatment.

Our opinion and anecdotal findings are that patients often experience good early pain relief and mobility following reverse shoulder replacement, obviating the need for sling immobilisation and the complications associated with this in the elderly.

The reverse shoulder replacement is also a useful salvage option in cases of failed fixation or hemiarthroplasty. ${ }^{64}$

There is little evidence to guide the timing of reverse shoulder arthroplasty, but one small retrospective study found that the use of the reverse shoulder arthroplasty as a primary procedure (rather than as revision for hemiarthroplasty or internal fixation) yielded better results. There was no significant difference in the outcomes if the reverse shoulder replacement was done for the acute fracture or for the treatment of a symptomatic malunion. ${ }^{65}$

\section{Conservative treatment}

This review would be incomplete if we did not report on the results of conservative treatment.

A recent Cochrane review concluded that 'there is high or moderate quality evidence that, compared with non-surgical treatment, surgery does not result in a better outcome at one and two years after injury for people with displaced proximal humeral fractures'. It is however 'likely to result in greater need for subsequent surgery'!

This finding was based on eight studies comparing outcomes between surgical and non-surgical groups but was dominated by the ProFHER study. 
These findings excluded fractures as a result of high energy trauma, two-part fractures involving the tuberosities, fracture dislocations and head splitting fractures. It also found insufficient randomised control trials to support a particular choice between different non-surgical or, when indicated, surgical interventions. ${ }^{21}$

The ProFHER study is a multicentre randomised clinical trial to assess the difference in outcomes between patients with proximal humerus fractures managed non-operatively and those managed surgically. Patients included were those with proximal humerus fractures involving the surgical neck where the attending surgeon would have considered surgery. As mentioned, exclusions included, among others, fractures isolated to the tuberosities, head splitting fractures, fracture dislocations, and open fractures or fractures with severe soft tissue injury which would preclude operative treatment Patients with significant medical comorbidities who could not tolerate anaesthesia were also excluded. ${ }^{20}$

The results showed no difference in outcomes at six,12 or 24 months between the surgical and non-surgical groups, and in contrast to the Cochrane review of 2012, there was also no difference in the complication rate and the number of patients requiring later surgical intervention or revision.

There were relatively small numbers of four-part fractures in either group, which will make recommendations in this subgroup of patients difficult. ${ }^{20}$

Will this change our treatment strategy?

With the large variation in fracture types in this study there might well be subgroups that do clearly benefit from surgery, but these remain unidentified. ${ }^{66}$

\section{Conclusion}

There appears to be a growing body of evidence that these fractures can and often should be managed conservatively. Two recent Cochrane reviews and the ProFHER randomised study found that surgical management did not confer better outcomes over conservative treatment. While this does not mean that surgery is contraindicated, it does make the patient selection for surgical intervention more difficult.

To complicate matters further, there is little evidence to support one surgical modality over the other.

This, combined with the number of new implants being developed and the industry-(market) driven pressures to use these implants (sometimes with little adequate clinical proof), makes decision making for the orthopaedic surgeon even more complex.

There remains little compelling evidence to guide decision making for the complex proximal humeral fracture in the elderly, and the decision needs to be made on a case-by-case basis taking into account the patient's comorbidities, the fracture pattern and characteristics, the attending surgeon's skill sets, and the availability of equipment.

It remains our opinion that too many of these fractures are undergoing surgical fixation unnecessarily.

That said, many elderly patients will not tolerate conservative treatment and sling immobilisation, and many are presenting with fracture patterns resembling 'young, high energy injuries' due to increased activity and longevity.

The decision to operate should then be made after discussing the pros and cons with the patient and their family.

\section{Ethics statement}

This article does not contain any studies with human or animal subjects performed by any of the authors.

\section{Declaration}

The authors declare authorship of this article and that they have followed sound scientific research practice. This research is original and does not transgress plagiarism policies.

\section{Author contributions}

It was a combined project, with each author providing literature review and equal input.

\section{ORCID}

BP Bernstein (iD) http://orcid.org/0000-0002-1859-4594

JP du Plessis (iD https://orcid.org/0000-0001-6469-7765

M Laubscher iD http://orcid.org/0000-0002-5989-8383

\section{References}

1. Hashmi F, Mayr E. A new nail with a locking blade for complex proximal humeral fractures. Eur. J. Orthop. Surg. [Internet]. 2016 [cited 2016 Aug 23]; Available from: http://link.springer.com/ article/10.1007/s00590-016-1817-4

2. Carbone S, Papalia M. The amount of impaction and loss of reduction in osteoporotic proximal humeral fractures after surgical fixation. Osteoporos. Int. 2016;27:627-33.

3. Coleman A, Clifft J. The effect of shoulder immobilization on balance in community-dwelling older adults. J. Geriatr. Phys. Ther. [Internet]. 2010 [cited 2016 Aug 23]; Available from: http://journals.Iww.com/jgpt/Abstract/2010/07000/ The_Effect_of_Shoulder_Immobilization_on_Balance.4.aspx

4. Lui D, Memon A, Kwan S, Mullett H. Computerized dynamic posturography analysis of balance in individuals with a shoulder stabilization sling. Eur. J. Trauma [Internet]. 2013 [cited 2016 Aug 23]; Available from: http://link.springer.com/article/10.1007/ s00068-013-0309-z

5. Rosengren BE, Karlsson M, Petersson I, Englund M. The 21st-century landscape of adult fractures: cohort study of a complete adult regional population. J. Bone Miner. Res. [Internet]. 2015 [cited 2016 Aug 23];30:535-42. Available from: http://doi. wiley.com/10.1002/jbmr.2370

6. Park $\mathrm{C}, \mathrm{Ha} \mathrm{Y}$, Jang $\mathrm{S}$, Jang $\mathrm{S}$, Yoon $\mathrm{H}$. The incidence and residual lifetime risk of osteoporosis-related fractures in Korea. J. Bone [Internet]. 2011 [cited 2016 Aug 23]; Available from: http://link. springer.com/article/10.1007/s00774-011-0279-3

7. Clinton J, Franta A, Polissar NL, Neradilek B, Mounce D, Fink HA, et al. Proximal humeral fracture as a risk factor for subsequent hip fractures. J. Bone Joint Surg Am. 2009 Mar 1;91(3):503-11. doi: 10.2106/JBJS.G.01529.

8. Calvo E, Morcillo D, Foruria A. Nondisplaced proximal humeral fractures: high incidence among outpatient-treated osteoporotic fractures and severe impact on upper extremity function and patient. J. Shoulder [Internet]. 2011 [cited 2016 Aug 23]; Available from: http://www.sciencedirect.com/science/article/pii/ S1058274610004088

9. Rüden $\mathrm{C}$ von, Augat P. Failure of fracture fixation in osteoporotic bone. Injury [Internet]. 2016 [cited 2016 Aug 23]; Available from: http://www.sciencedirect.com/science/article/pii/ S0020138316470026

10. Van Staa TP, Dennison EM, Leufkens HGM, Cooper C. Epidemiology of fractures in England and Wales. Bone. 2001 Dec;29(6):517-22.

11. Yoo J-H, Moon S-H, Ha Y-C, Lee DY, Gong HS, Park SY, et al Osteoporotic Fracture: 2015 Position Statement of the Korean Society for Bone and Mineral Research. J. Bone Metab. [Internet]. 2015 [cited 2016 Aug 23];22:175. Available from: http://synapse. koreamed.org/DOlx.php?id=10.11005/jbm.2015.22.4.175

12. Black DM, Delmas PD, Eastell R, et al. Once-yearly zoledronic acid for treatment of postmenopausal osteoporosis. N. Engl. J. Med. 2007 May 3;356(18):1809-22. [Internet]. [cited 2016 Aug 23]; Available from: http://www.nejm.org/doi/full/10.1056/ nejmoa067312

13. Bawa H, Weick J, Dirschl D. Anti-osteoporotic therapy after fragility fracture lowers rate of subsequent fracture. J. Bone Jt. Surg. Am. [Internet]. 2015 [cited 2016 Aug 23]; Available from: http://jbjs.org/ content/97/19/1555.abstract

14. Viprey M, Caillet P, Canat G, Jaglal S, Haesebaert J. Low osteoporosis treatment initiation rate in women after distal forearm 
or proximal humerus fracture: a healthcare database nested cohort study. PLoS One [Internet]. 2015 [cited 2016 Aug 23] Available from: http://journals.plos.org/plosone/article?id=10.1371/ journal.pone.0143842

15. Díez-Pérez A, Hooven F, Adachi J, Adami S. Regional differences in treatment for osteoporosis. The Global Longitudinal Study of Osteoporosis in Women (GLOW). Bone [Internet]. 2011 [cited 2016 Aug 23]; Available from: http://www.sciencedirect.com/science/ article/pii/S8756328211009811

16. Neer CS. Displaced proximal humeral fractures. II. Treatment of three-part and four-part displacement. J. Bone Joint Surg. Am. [Internet]. 1970 [cited 2016 Aug 23];52:1090-103. Available from: http://www.ncbi.nlm.nih.gov/pubmed/5455340

17. Siwach R, Singh R, Rohilla R, Kadian V. Internal fixation of proximal humeral fractures with locking proximal humeral plate (LPHP) in elderly patients with osteoporosis. J. Orthop. [Internet]. 2008 [cited 2016 Aug 23]; Available from: http://link.springer.com/ article/10.1007/s10195-008-0014-6

18. Röderer G, Erhardt J, Kuster M, Vegt P, Bahrs C. Second generation locked plating of proximal humerus fractures-a prospective multicentre observational study. Internationa [Internet]. 2011 [cited 2016 Aug 23]; Available from: http://link. springer.com/article/10.1007/s00264-010-1015-7

19. Bogner R, Hübner C, Matis N, Auffarth A. Minimally-invasive treatment of three-and four-part fractures of the proximal humerus in elderly patients. Bone Jt. [Internet]. 2008 [cited 2016 Aug 23]; Available from: http://www.bjj.boneandjoint.org.uk/ content/90-B/12/1602.short

20. Rangan $A$, Handoll $H$, Brealey $S$, et al:; PROFHER Tria Collaborators. Surgical vs nonsurgical treatment of adults with displaced fractures of the proximal humerus: the PROFHER randomized clinical trial. JAMA [Internet]. 2015 [cited 2016 Aug 23]; Available from: http://jama.jamanetwork.com/article.aspx?arti cleid=2190987\&version=meter+at+null\&module=meter-Links\&pg ype=Blogs\&contentld=\&mediald=\%25\%25ADID\%25\%25\&referrer $=\&$ priority=true\&action=click\&contentCollection=meter-links-click

21. Handoll $\mathrm{H}$, Brorson $\mathrm{S}$. Interventions for treating proximal humeral fractures in adults. Cochrane Libr. [Internet]. 2015 [cited 2016 Aug 23]; Available from: http://onlinelibrary.wiley.com/ doi/10.1002/14651858.CD000434.pub4/pdf

22. Hertel $R$, Hempfing $A$, Stiehler $M$, Leunig $M$. Predictors of humeral head ischemia after intracapsular fracture of the proximal humerus. J. Shoulder Elb. [Internet]. 2004 [cited 2016 Aug 24] Available from: http://www.sciencedirect.com/science/article/pii/ S1058274604000795

23. Giannotti S, Bottai V, Dell'osso G, Donati D, Bugelli G, De Paola $\mathrm{G}$, et al. Indices of risk assessment of fracture of the proximal humerus. Clin. Cases Miner. Bone Metab. [Internet]. CIC Edizioni Internazionali; 2012 [cited 2016 Aug 24];9:37-9. Available from http://www.ncbi.nlm.nih.gov/pubmed/22783334

24. Mather J, MacDermid JC, Faber KJ, Athwal GS, Athwal GS, Sperling JW, et al. Proximal humerus cortical bone thickness correlates with bone mineral density and can clinically rule out osteoporosis. J. Shoulder Elb. Surg. [Internet]. Elsevier; 2013 [cited 2016 Aug 24];22:732-8. Available from: http://linkinghub.elsevier com/retrieve/pii/S1058274612003643

25. Krappinger D, Roth T, Gschwentner M, Suckert A. Preoperative assessment of the cancellous bone mineral density of the proximal humerus using CT data. Skeletal Radiol. [Internet]. 2012 [cited 2016 Aug 23]; Available from: http://link.springer.com/ article/10.1007/s00256-011-1174-7

26. Krappinger D, Bizzotto N, Riedmann S. Predicting failure after surgical fixation of proximal humerus fractures. Injury [Internet]. 2011 [cited 2016 Aug 23]; Available from: http://www. sciencedirect.com/science/article/pii/S002013831100026X

27. Maier D, Jaeger M, Izadpanah K, Strohm PC, Suedkamp NP. Proximal humeral fracture treatment in adults. J. Bone Joint Surg. Am. [Internet]. 2014 [cited 2016 Aug 23];96:251-61. Available from: http://www.ncbi.nlm.nih.gov/pubmed/24500588

28. Min MW, Davidovitch R. Three-and four-part proximal humerus fractures: evolution to operative care. Bull. NYU [Internet]. 2012 [cited 2016 Aug 23]; Available from: http://search.proquest. com/openview/6b0a453ee1041d6b685802466b4a6e27/1 ?pq-origsite=gscholar

29. Resch H, Hübner $\mathrm{C}$, Schwaiger R. Minimally invasive reduction and osteosynthesis of articular fractures of the humeral head.
Injury [Internet]. 2001 [cited 2016 Aug 23]; Available from: http:// www.sciencedirect.com/science/article/pii/S0020138301000584

30. Bell J, Leung B, Spratt K, Koval K, Weinstein J. Trends and variation in incidence, surgical treatment, and repeat surgery of proximal humeral fractures in the elderly. J. Bone Jt. Surg. [Internet]. 2011 [cited 2016 Aug 23]; Available from: http://jbjs.org/ content/93/2/121.abstract

31. Dean B, Jones L, Palmer A. A review of current surgical practice in the operative treatment of proximal humeral fractures. Bone $\mathrm{Jt}$. [Internet]. 2016 [cited 2016 Aug 23]; Available from: http://www.bjr. boneandjoint.org.uk/content/5/5/178.abstract

32. Cornell $\mathrm{C}$, Ayalon O. Evidence for success with locking plates for fragility fractures. HSS J. [Internet]. 2011 [cited 2016 Aug 23]; Available from: http://link.springer.com/article/10.1007/ s11420-010-9194-8

33. Gardner MJ, Weil Y, Barker JU, Kelly BT, Helfet DL, Lorich DG. The importance of medial support in locked plating of proximal humerus fractures. J. Orthop. Trauma [Internet]. 2007 [cited 2016 Aug 23];21:185-91. Available from: http://content. wkhealth.com/linkback/openurl?sid=WKPTLP:landingpage \&an=00005131-200703000-00006

34. Jung W, Moon E, Kim S. Does medial support decrease major complications of unstable proximal humerus fractures treated with locking plate? BMC [Internet]. 2013 [cited 2016 Aug 23]; Available from: https://bmcmusculoskeletdisord.biomedcentral.com/ articles/10.1186/1471-2474-14-102

35. Lin S, Tsai Y, Yang T, Shen S. Medial calcar support and radiographic outcomes of plate fixation for proximal humeral fractures. BioMed Res. [Internet]. 2015 [cited 2016 Aug 23]; Available from: http://www.hindawi.com/journals/ bmri/2015/170283/abs/

36. Silverstein M, Yirenkyi K. Analysis of failure with the use of locked plates for stabilization of proximal humerus fractures. Bull. NYU [Internet]. 2015 [cited 2016 Aug 23]; Available from: http:// go.galegroup.com/ps/i.do?id=GALE\%7CA430394902\&sid=google Scholar\&v=2.1\&it=r\&linkaccess=fulltext\&issn=19369719\&p=AON $E \& s w=w$

37. Katthagen J, Schwarze M, Warnhoff M, Voigt C. Influence of plate material and screw design on stiffness and ultimate load of locked plating in osteoporotic proximal humeral fractures. Injury [Internet]. 2016 [cited 2016 Aug 23]; Available from: http://www. sciencedirect.com/science/article/pii/S0020138316000061

38. Badman B, Frankle M, Keating C, Henderson L. Results of proximal humeral locked plating with supplemental suture fixation of rotator cuff. J. Shoulder [Internet]. 2011 [cited 2016 Aug 23]; Available from: http://www.sciencedirect.com/science/article/pii/ S1058274610003873

39. Cho C, Jung G, Song K. Tension suture fixation using 2 washers for proximal humeral fractures. Orthopedics [Internet]. 2012 [cited 2016 Aug 23]; Available from: http://www.healio.com/orthopedics/ journals/ortho/2012-3-35-3/\%7B25dea13f-24e8-4323-8aa3$95 \mathrm{e} 0 \mathrm{bb} 08 \mathrm{a} 672 \% 7 \mathrm{D} /$ tension-suture-fixation-using-2-washers-forproximal-humeral-fractures

40. Park J, An J, Oh J. Open intramedullary nailing with tension band and locking sutures for proximal humeral fracture: hot air balloon technique. J. Shoulder Elb. Surg. [Internet]. 2006 [cited 2016 Aug 23]; Available from: http://www.sciencedirect.com/science/article/ pii/S1058274606000711

41. Dilisio $M$, Nowinski $R$, Hatzidakis $A$. Intramedullary nailing of the proximal humerus: evolution, technique, and results. J. Shoulder [Internet]. 2016 [cited 2016 Aug 23]; Available from: http://www. sciencedirect.com/science/article/pii/S1058274615006308

42. Baltov A, Mihail R, Dian E. Complications after interlocking intramedullary nailing of humeral shaft fractures. Injury [Internet]. 2014 [cited 2016 Aug 24]; Available from: http://www. sciencedirect.com/science/article/pii/S0020138313005214

43. Clavert P, Hatzidakis A, Boileau P. Anatomical and biomechanical evaluation of an intramedullary nail for fractures of proximal humerus fractures based on tuberosity fixation. Clin. Biomech. [Internet]. 2016 [cited 2016 Aug 23]; Available from: http://www. sciencedirect.com/science/article/pii/S0268003315003290

44. Wong J, Newman J, Gruson K. Outcomes of intramedullary nailing for acute proximal humerus fractures: a systematic review. J. Orthop. [Internet]. 2015 [cited 2016 Aug 23]; Available from: http:// link.springer.com/article/10.1007/s10195-015-0384-5 
45. Fazal M, Baloch I, Ashwood N. Polarus nail fixation for proximal humeral fractures. J. Orthop. [Internet]. 2014 [cited 2016 Aug 23]; Available from: http://search.proquest.com/openview/228339aa7d cff5a168bbd388b3df65e4/1?pq-origsite=gscholar

46. Ueyama H, Yano K, Kanemura M, Gotani H, Ito S. Clinical outcomes and prognostic factors depending on implant design in the treatment of proximal humeral fractures: A retrospective study. J. Orthop. [Internet]. 2016 [cited 2016 Aug 23]; Available from: http://www.sciencedirect.com/science/article/pii/ S0972978X16300320

47. Lopiz Y, Garcia-Coiradas J, Garcia-Fernandez C. Proximal humerus nailing: a randomized clinical trial between curvilinear and straight nails. J. Shoulder [Internet]. 2014 [cited 2016 Aug 23]; Available from: http://www.sciencedirect.com/science/article/pii/ S1058274613004709

48. Spiegelberg B, Riley N, Taylor G. Risk of injury to the axillary nerve during antegrade proximal humeral blade nail fixationAn anatomical study. Injury [Internet]. 2014 [cited 2016 Aug 23]; Available from: http://www.sciencedirect.com/science/article/pii/ S0020138314002459

49. Wang G, Mao Z, Zhang L. Meta-analysis of locking plate versus intramedullary nail for treatment of proximal humeral fractures. $J$. Orthop. Surg. Res. [Internet]. 2015 [cited 2016 Aug 23]; Available from: https://josr-online.biomedcentral.com/articles/10.1186/ s13018-015-0242-4

50. Röderer G, Scola A, Schmölz W, Gebhard F, Windolf M. Biomechanical in vitro assessment of screw augmentation in locked plating of proximal humerus fractures. Injury [Internet]. 2013 [cited 2016 Aug 23]; Available from: http://www. sciencedirect.com/science/article/pii/S0020138313002362

51. Kammerlander C, Neuerburg C, Verlaan J. The use of augmentation techniques in osteoporotic fracture fixation. Injury [Internet]. 2016 [cited 2016 Aug 23]; Available from: http://www. sciencedirect.com/science/article/pii/S0020138316470075

52. Katthagen J, Schwarze M, Meyer-Kobbe J, Voigt C. Biomechanical effects of calcar screws and bone block augmentation on medial support in locked plating of proximal humeral fractures. Clin. Biomech. [Internet]. 2014 [cited 2016 Aug 23]; Available from: http://www.sciencedirect.com/science/article/pii/ S0268003314001405

53. Kennedy J, Feerick E, McGarry P. Effect of calcium triphosphate cement on proximal humeral fracture osteosynthesis: a finite element analysis. J. Orthop. Surg. (Hong Kong). [Internet]. 2013 [cited 2016 Aug 23]; Available from: http://search.proquest. com/openview/9e7065cd0fa3bcc60776c607ceeb6ad1/1 ?pq-origsite $=$ gscholar

54. Kathrein S, Kralinger F, Blauth M, Schmoelz W. Biomechanical comparison of an angular stable plate with augmented and non-augmented screws in a newly developed shoulder test bench. Clin. Biomech. [Internet]. 2013 [cited 2016 Aug 23]; Available from: http://www.sciencedirect.com/science/article/pii/ S026800331200294X

55. Schliemann B, Seifert R, Rosslenbroich S. Screw augmentation reduces motion at the bone-implant interface: a biomechanical study of locking plate fixation of proximal humeral fractures. J. Shoulder [Internet]. 2015 [cited 2016 Aug 23]; Available from: http://www.sciencedirect.com/science/article/pii/ S1058274615003481

56. Matassi F, Angeloni R, Carulli C, Civinini R, Bella L Di. Locking plate and fibular allograft augmentation in unstable fractures of proximal humerus. Injury [Internet]. 2012 [cited 2016 Aug 23]; Available from: http://www.sciencedirect.com/science/article/pii/ S0020138312003002

57. Panchal K, Jeong J, Park S, Kim W, Min H. Clinical and radiological outcomes of unstable proximal humeral fractures treated with a locking plate and fibular strut allograft. International [Internet]. 2016 [cited 2016 Aug 23]; Available from: http://link.springer.com/ article/10.1007/s00264-015-2950-0

58. Euler S, Kralinger F, Hengg C. Allograft augmentation in proximal humerus fractures. Oper. Orthopädie [Internet]. 2016 [cited 2016 Aug 23]; Available from: http://link.springer.com/article/10.1007/ s00064-016-0446-8
59. Chen H, Ji X, Zhang Q, Liang X. Clinical outcomes of allograft with locking compression plates for elderly four-part proximal humerus fractures. J. Orthop. Surg. Res. [Internet]. 2015 [cited 2016 Aug 23]; Available from: https://josr-online.biomedcentral.com/ articles/10.1186/s13018-015-0258-9

60. Goetzen M, Windolf M, Schmoelz W. Augmented screws in angular stable plating of the proximal humerus: What to do when revision is needed? Clin. Biomech. [Internet]. 2014 [cited 2016 Aug 23]; Available from: http://www.sciencedirect.com/science/article/pii/ S0268003314002046

61. Lieshout $\mathrm{E}$ Van, Alt V. Bone graft substitutes and bone morphogenetic proteins for osteoporotic fractures: what is the evidence? Injury [Internet]. 2016 [cited 2016 Aug 23]; Available from: http://www.sciencedirect.com/science/article/pii/ S0020138316300110

62. Schliemann B, Wähnert D, Theisen C, Herbort M. How to enhance the stability of locking plate fixation of proximal humerus fractures? An overview of current biomechanical and clinical data. Injury [Internet]. 2015 [cited 2016 Aug 23]; Available from: http://www. sciencedirect.com/science/article/pii/S0020138315002168

63. Schairer W, Nwachukwu B, Lyman S. Reverse shoulder arthroplasty versus hemiarthroplasty for treatment of proximal humerus fractures. J. Shoulder [Internet]. 2015 [cited 2016 Aug 23]; Available from: http://www.sciencedirect.com/science/article/ pii/S1058274615001597

64. Shannon S, Wagner E, Houdek M. Reverse shoulder arthroplasty for proximal humeral fractures: outcomes comparing primary reverse arthroplasty for fracture versus reverse arthroplasty after failed. J. Shoulder [Internet]. 2016 [cited 2016 Aug 23]; Available from: http://www.sciencedirect.com/science/article/pii/ S1058274616001208

65. Dezfuli B, King J, Farmer K, Struk A, Wright T. Outcomes of reverse total shoulder arthroplasty as primary versus revision procedure for proximal humerus fractures. J. Shoulder Elbow Surg. 2016 Jul;25(7):1133-7. doi: 10.1016/j.jse.2015.12.002.

66. Dean BJF, Jones LD, Palmer AJR, Macnair RD, Brewer PE, Jayadev $C$, et al. A review of current surgical practice in the operative treatment of proximal humeral fractures: Does the PROFHER trial demonstrate a need for change? Bone Joint Res. [Internet]. Bone and Joint Research; 2016 [cited 2016 Aug 23];5:178-84. Available from: http://www.ncbi.nlm.nih.gov/ pubmed/27179004 